\title{
Do Stressed Women have Abnormal Glucose Level?
}

\author{
Amirul Adli M., Gaushinee V., Abdullah M. S., Rafaee R., Syahirah M. T., Amirah M., \\ Chut Kartika B., Lily Alma Nadirah A. J., Sabariah A. H. \\ Faculty of Medicine, Cyberjaya University College of Medical Sciences, Malaysia
}

\section{Article Info}

Article history:

Received May 4, 2017

Revised May 28, 2017

Accepted May 31, 2017

\section{Keywords:}

Coping skills

Diabetes mellitus

Pre diabetes

Stress

Women

\begin{abstract}
Stress is a physical, mental and emotional response to a challenging event and is a normal part of everyone's life. It has been linked to suppression of the immune system and could increase the risk of getting ill or alter the course of existing illness. Studies show that stress is associated with increased HBA1c, especially in females. Therefore the purpose of this study was to determine the prevalence of stress with abnormal glucose value among the women community. A cross-sectional study was conducted among 168 residents of Mukim Sg. Pelek, Sepang, Selangor. Participants were selected through a simple random sampling and were asked to answer questionnaires provided. The Depression, Stress and Anxiety (DASS-21) scale was used to determine the prevalence of stress and random blood sugar (RBS) for measurement of the glucose level. Data was analyzed using Statistical Package Social Sciences (SPSS) version 20 and Chi-square analyses for determining the association between variables. The study found that $58.3 \%$ of the stressed women in the community have abnormal blood glucose level, which indicated that the risk of getting diabetes is slightly high. This finding has important implication for designing strategic plans for intervention program on awareness towards coping with stress positively.
\end{abstract}

Copyright @ 2017 Institute of Advanced Engineering and Science. All rights reserved.

\section{Corresponding Author:}

Sabariah Abd Hamid,

Faculty of Medicine,

Cyberjaya University College of Medical Sciences,

Malaysia.

Email: sabariah@cybermed.edu.my

\section{INTRODUCTION}

Stress is a physical, mental and emotional response to a challenging event and often referred to as the fight-or-flight response, which occurs automatically when feel threatened. Stressors can be external (from the environment, psychological, or social situations) or internal (illness, or from a medical procedure) [1]. The prevalence of stress among community in Hulu Langat, Selangor was 33.6\% [2] and a study by APA in United States showed $22 \%$ of population with stress [3]. In 2014, females in India from rural and backward settings showed a $15 \%$ higher level of stress compared to males at the same place [4]. According to the American Psychological Association, 23\% of females compared to 15\% males reported being stressed and this impacted their lives [5]. A research done in Malaysia stated that women are more stressed compared to men in university settings [6].

Stress, whether positive or negative, is a normal part of everyone's life. Negative stress, however, diminishes the quality of life [7]. Stress can affect our quality of life through different aspects such as social relationship and health [8]. Moreover, stressful life events are associated with a significantly increased risk for mortality, mediated by smoking, cardiovascular disease and type 2 diabetes [9].

The occurrence of diabetes around the world was estimated to be $2.8 \%$ in the year 2000 and is to increase to $4.4 \%$ by the year 2030 [10]. In some Asian country, for instance, Japan, 55.826 subjects (24.826 men and 31.000 women) Japanese aged 40-69 years were followed for 10 years and a self-administered 
questionnaire on medical conditions including diabetes and other lifestyle factors was completed at baseline and 5 and 10 years later. The result shows the risk of diabetes increased with an increasing stress level, for both gender, where the multivariate adjusted odds ratios for high stress compared with low stress were 1.36 (95\% CI 1.13-1.63) among men and 1.22 (95\% CI 0.98-1.51) among women [11]. Diabetes has become one of the major causes for kidney failure, new cases of blindness, cardiovascular disease and stroke [12]. There were 3.2 million diabetic patients in Malaysia in the year 2014 [13]. In Selangor, there is a significant correlation between an increased HBA1c and stress, whereby $89.5 \%$ of diabetic respondents agreed that diabetes caused stressed or vice versa [14].

A study done in Pondicherry, India shows that stress was associated with Diabetes Mellitus (OR, 8) [15]. When stress is experienced in the postprandial period, acute psychological stress significantly increases glucose concentrations in patients with type 2 diabetes, where during the stress-test day, when the Trier Social Stress Test was applied 75 min after the intake of a standard meal, the glucose concentrations were significantly higher compared with the control day (mean difference $1.5 \mathrm{mmol} / 1,95 \% \mathrm{CI} 0.5-2.4, \mathrm{P}=0.003$ ). Whereas, in the fasting state, glucose concentrations slightly decreased during the control day but remained stable on the stress-test day (mean difference compared with the control day $0.7 \mathrm{mmol} / 1,95 \% \mathrm{CI}-0.7$ to 2.0 , $\mathrm{P}=0.31$ ) [16].

In 2001, Young and Mustard in their study, shows the prevalence of undiagnosed diabetes in the adult population of Manitoba was 2.2\% and undiagnosed cases accounted for about one-third of all diabetes cases. Individuals with undiagnosed diabetes had an unfavorable lipid profile, higher blood pressure and obesity indices and more likely to be admitted to hospital at least once (odds ratio $1.23,95 \%$ CI 0.40-3.79), compared with normoglycemic individuals [17].

A study in Canada also report pre diabetes or undiagnosed diabetes, is neither a benign nor a quiescent state, but represents a serious clinical and public health concern. [18]. Treating hyperglycemia to prevent complications would be preferable to and more effective than treating these complications after they arise. However, prevalence of 'pre diabetes' and 'undiagnosed' diabetes depends on the underlying (true) diabetes prevalence, screening coverage, the definition of diabetes, and if based on self-report of diagnosis, the degree of recall bias [19]. Pre diabetes was defined as having abnormal glucose levels that were not sufficient to meet the criteria for diabetes diagnosis, whereas undiagnosed diabetes was defined as not having self-reported type 2 diabetes, but having blood glucose measures that met current diagnostic guidelines for type 2 diabetes [18].

The pre diabetes or undiagnosed cases represent the unseen but clinically important burden of diabetes, with significant concurrent metabolic derangements and a long-term impact on health care use. Therefore, early detection and management of pre diabetes or undiagnosed diabetes are important, in order to minimize the risk of complications and associated health care costs. Thus, this study was designed to determine the prevalence of stress with abnormal glucose value among the women community of Mukim Sg Pelek, Sepang, Selangor.

\section{MATERIALS AND METHODS}

A cross-sectional study was conducted in a housing area in Mukim Sungai Pelek, Sepang, Selangor, Malaysia. The area has been chosen as the community to be studied was multi-racial residents and is accessible. Stratified random sampling was used to classify the houses into two groups, single-storey and double-storey. Systematic random sampling was then used to pick the houses in each stratum accordingly and simple random sampling using drawing lots to choose the respondents in the house. Only Malaysians aged 18 until 75 years old and had been the residents for at least three months were used as samples. Residents with mental and hearing impairment were excluded in this survey. Data were collected through:

i. Assisted questionnaire interview which includes DASS 21, to assess the stress level of the community [20].

Stress Categories: Normal $:<8$, Stress $: \geq 8$

ii. Random blood sugar was taken to assess the abnormal glucose level. Measurement adapted from the Clinical Practice Guidelines Management of Type 2 Diabetes Mellitus, Ministry of Health Malaysia, $4^{\text {th }}$ Edition [21].

RBS level: Normal: $<7.8 \mathrm{mmol} / \mathrm{L}$, Risk: $7.8-11.0 \mathrm{mmol} / \mathrm{L}$, Diabetic: $\geq 11.1 \mathrm{mmol} / \mathrm{L}$

In the symptomatic individual, one abnormal glucose value is diagnostic. In the asymptomatic individual, two abnormal glucose values are required. Data was analyzed using Statistical Package Social Sciences (SPSS) version 20. Chi-square test analyses the association between stress status (independent variable) and pre diabetes mellitus (dependent variable). 


\section{RESULTS AND ANALYSIS}

A total of 168 participants participated in this study, giving an overall response rate of $97.7 \%$. Out of 168 respondents, 109 of them were women, with the percentage of $64.9 \%$. Among the women respondents, $22 \%$ were having stress as shown in Table 1.

Table 1. Prevalence of Stress among Women

\begin{tabular}{ccc}
\hline Stress status & No. & $\%$ \\
\hline Normal & 87 & 78.0 \\
Stress & 24 & 22.0 \\
Total & 109 & 100 \\
\hline
\end{tabular}

Table 2 shows that the prevalence of stress among woman was the highest $(37.5 \%)$ within the age 18-29 while the age 60 and above has the lowest prevalence $(8.3 \%)$. The Indian women show the highest prevalence of stress which was $62.5 \%$ followed by Malay and Chinese with the percentage of $29.2 \%$ and $8.3 \%$ respectively. Almost $71 \%$ of married women and $45.8 \%$ of housewives were stressed in this study.

Table 2. Stress Status among Women by Socio-Demographic

\begin{tabular}{|c|c|c|c|}
\hline \multirow{2}{*}{\multicolumn{2}{|c|}{ Socio-demographic }} & \multicolumn{2}{|c|}{ Stress Status } \\
\hline & & Frequency & Percentage \\
\hline \multirow[t]{5}{*}{ Age group } & $18-29$ & 9 & 37.5 \\
\hline & $30-39$ & 5 & 20.8 \\
\hline & $40-49$ & 3 & 12.6 \\
\hline & $50-59$ & 5 & 20.8 \\
\hline & $\geq 60$ & 2 & 8.3 \\
\hline \multirow[t]{3}{*}{ Ethnic } & Malay & 7 & 29.2 \\
\hline & Chinese & 2 & 8.3 \\
\hline & Indian & 15 & 62.5 \\
\hline \multirow[t]{4}{*}{ Marital } & Single & 4 & 16.7 \\
\hline & Married & 17 & 70.8 \\
\hline & Divorce & 1 & 4.2 \\
\hline & Widowed & 2 & 8.3 \\
\hline \multirow[t]{7}{*}{ Occupation } & Government & 7 & 8.3 \\
\hline & Private & 5 & 20.8 \\
\hline & Student & 3 & 12.6 \\
\hline & Housewives & 11 & 45.8 \\
\hline & Pensioner & 2 & 8.3 \\
\hline & Others & 1 & 4.2 \\
\hline & Total & 24 & 100 \\
\hline
\end{tabular}

Family problem was among the highest $(29.6 \%)$ cause of stress to women respondents. Other causes were work $(20.4 \%)$, financial $(16.7 \%)$ and health problem $(16.7 \%)$ as shown in Table 3.

Table 3. Causes of Stress among Stressed Women

\begin{tabular}{|c|c|c|}
\hline Causes of Stress & No. & $\%$ \\
\hline Education & 3 & 5.5 \\
\hline Family & 16 & 29.6 \\
\hline Relationship & 6 & 11.1 \\
\hline Financial & 9 & 16.7 \\
\hline Work & 11 & 20.4 \\
\hline Health & 9 & 16.7 \\
\hline Total & 54 & 100 \\
\hline
\end{tabular}

Among women who were stressed, $58.3 \%$ of them have abnormal glucose level at pre diabetes status. While among those who were at pre diabetes status, only $29.8 \%$ were stressed, however it was not statistically significant $(\mathrm{p}>0.05)$. Therefore there was no association between stress and pre diabetes among women in Mukim Sg. Pelek, Sepang is shown in Table 4. 
Table 4. Association between Stress and Pre Diabetes Status among Stressed Women

\begin{tabular}{cccc}
\hline & \multicolumn{3}{c}{ Pre Diabetes Status } \\
Stress Status & Yes n (\%) & No n $(\%)$ & P value \\
\hline Yes & $14(29.8)$ & $10(16.1)$ & \\
No & $33(70.2)$ & $43(83.9)$ & 0.088 \\
Total & $47(100)$ & $62(100)$ & \\
\hline$\chi^{2}=3.518$ & &
\end{tabular}

Table 5 shows that women who were stressed coped their stress by keeping calm with the percentage of $15.8 \%$ and followed by talking to someone, relaxing and thinking, with the percentage of $12.6 \%$ respectively. Only $4.2 \%$ of the respondents coped their stress with massage, $5.3 \%$ went for recreation and $6.3 \%$ expressed in words.

Table 5. Stress Coping Skills among Stressed Women

\begin{tabular}{lcc}
\hline \multicolumn{1}{c}{ Stress Coping Skill } & No. & $\%$ \\
\hline Keep calm & 15 & 15.8 \\
Exercise & 11 & 11.7 \\
Worship & 10 & 10.5 \\
Relax & 12 & 12.6 \\
Breathing technique & 8 & 8.4 \\
Express in words & 6 & 6.3 \\
Talk to someone & 12 & 12.6 \\
Massage & 4 & 4.2 \\
Recreation & 5 & 5.3 \\
Thinking & 12 & 12.6 \\
\multicolumn{1}{c}{ Total } & 95 & 100 \\
\hline
\end{tabular}

\section{DISCUSSION}

Gender difference has an effect on prevalence of stress, where in recent studies done in Malaysia shows the prevalence of stress was higher among females (30.8\%) as compared to males (27.6\%) [22]. However, the prevalence of stressed women in our study was $22.0 \%$, which also lower than prevalence of stressed among American women (32) [23] and India (87\%) [24]. The prevalence of stress among women in this study could be correlated with the highest prevalence of stress among housewife and these could be due to housework factors as shown in Europe, where women tended to perceive higher degrees of houseworkrelated stress with the percentage $15.3 \%$ for low stress, $29.1 \%$ for moderate stress and $33 \%$ for high stress [25]. The traditional roles of women as homemaker are still continuing and in demand in our society which subsequently lead to the major stress among women [26]. The high prevalence in married women also could be due to parental factor as reported by where a study in Sweden women reported higher levels of parental stress (60\%) compared to men [27]. In America married women reported higher levels of stress than single women, with one-third (33\%) reporting that they have experienced a great deal of stress in the past month (8, 9 or 10 on a 10-point scale) compared with one in five $(22 \%)$ of single women. Similarly, more married women reported that their stress have increased over the past five years (56\% vs. $41 \%$ of single women). Single women are also more likely than married women to say they feel they are doing enough to manage their stress (63\% vs. 51\%) [28].

Stress and anxiety are the offshoots of inadequate interaction with the environment and family environment is the chief cause [29]. This may be due to daily conflicts that arise between family members which can affect their mental health. In family setting, women have to consider household responsibilities, marital adjustment, child caring issues and family relationships [30]. The high percentage among married women may also due to problems with the partner as shown in study in South Chennai, India, where $9.5 \%$ of stress women have family history of couple misunderstanding and $3.0 \%$ were ill-treated by their family members [31]. Whereas a study in Selangor shows the highest stressful life event is relationship with family (34.1\%) [32]. Although our study showed lower prevalence than Siti Fatimah, but relationship was among the five causes of stress among our respondents with percentage of $11 \%$..

In Malaysia, the influx of women into the workforce has been one of the dominant global social trends during the past thirty [33]. Studies show that work related factors are the common causes of daily stress in Malaysia with prevalence of 31.3\% [34] and 34\% in Australia [35]. In our study, 20.4\% of the female were having stress due to work, where $8.3 \%$ were working in government sector and $20.8 \%$ in the private sector. This could be due to bad psychological atmosphere at work, where $3.5 \%$ women are stressed due to bad psychological atmosphere at work [31]. 
There are several reviews of the literature that suggest psychological stress can adversely affect glycemic control among individuals with diabetes [36] with two mechanisms by which stress can affect metabolic control. First, stress may indirectly affect metabolic control by disrupting regimen adherence. That is, stress may detract from self-care behavior which then leads to poor metabolic [37]. Second, researchers have suggested stress may directly influence blood glucose levels via physiological mechanisms [38]. R. Chang in his cross-sectional analyses [39] did not show links of total stress to blood glucose but did show that blood glucose was related to one specific domain of stress, which is personal stress. However, Joseph reports excessive stress is a major barrier to effective glucose [40]. A study by Pouwer, Kupper, and Adriananse [41] show general emotional stress and anxiety, sleeping problems, anger, and hostility are associated with an increased risk for the development of type 2 diabetes. Another study done by Tsujii, Hayashino, and Ishii [42] shows patients in the high-PAID group (emotional distress) had greater risk for poor glycemic control by $67 \%$. The study also suggested that stress causes diabetes mellitus. National Health Morbidity Survey 2015 [22] reports the prevalence of diabetes mellitus is $17.5 \%$, whereas the prevalence of undiagnosed diabetes is $8.9 \%$, much lower than national survey. However, the estimated prevalence of undiagnosed diabetes by Laura et al. [18] is $1.13 \%$ (95\% CI 0.79, 1.62).

Women have higher prevalence of diabetes mellitus, compared to men. Studies done by Minhat et al. [43], Johari et al. [44] and NHMS [22] show prevalence of diabetes in females are much higher than males $(59 \%$ vs $41 \%, 48.1 \%$ vs $36.3 \%, 18.3 \%$ vs $16.7 \%$, respectively). However, a study in Riyadh, Saudi Arabia shows the prevalence of diabetes in males (77.3\%) is higher than females (22.7\%) [45]. This is because the male tend to have sedentary lifestyles that contribute to get diabetes mellitus, as mentioned by Letchuman et al. [46], where increasing urbanization and sedentary lifestyle are the main factors of increasing diabetes prevalence rate. Laura et al. [18] also report the proportion of undiagnosed diabetes prevalence was higher for males compared with females (22\% vs. $18 \%)$, whereas under the $\mathrm{HbA}_{1 \mathrm{c}}$-only criterion, the proportion of undiagnosed diabetes prevalence was lower for males compared with females ( $37 \%$ vs. $46 \%$ ). As for pre diabetes, the prevalence of is estimated to be $4.3 \%$ according to the FPG-only diagnostic criterion, and is significantly higher for males compared with females. In a study done in Missouri on diabetic patients, $14.1 \%$ and $27.3 \%$ of patients have been identified as highly and moderately distressed [47], whereas $12.04 \%$ of the Japanese type 2 diabetes patients have been found to have diabetesrelated emotional distress, with PAID score $\geq 40$ [42]. Both studies also have reported that there were a significant association between distress and poor glycemic control i.e. having longer duration of diabetes $(P<0.0003)$ and higher HbA1c levels $(P<0.0001)$. The results are similar with a study done in Malaysia by Kaur et al. [14], where the HbA1c level was more than $8.5 \%(\mathrm{p}<0.05)$.

A research was done in Dutch city of Hoorn shows that there is an association of stress with Diabetes Mellitus $(P<0.001)$ [9]. While a study done in the Republic of Croatia shows that poor glycemic control is more frequent in patients who had high level of stress, where it is significantly associated with increased HbA1c $(P<0.001)$ [48]. Furthermore, another study on 1.5 million men with diabetes mellitus were tested with stress resilience and those who do not cope with stress has association with type 2 diabetes mellitus, $(P<0.001)$ when adjusted with body mass index $(\mathrm{BMI})$, family history of diabetes and individual and neighborhood socioeconomic factors [49]. However, our study showed that there was no association between stress and pre diabetes status among women in Mukim Sg. Pelek, Sepang. Type 2 diabetes mellitus (non-insulin-dependent) is not only one of the most complicated diseases managed in primary care, but patients with diabetes experience a decrease in their 'quality of life' compared with healthy individuals and that functional health status decreases as complications become more severe [50]. Richard et al, [51] states in their report, $32 \%$ of patients who have stress management show lower level of $\mathrm{HbA}_{1 \mathrm{c}}$ compared to only $12 \%$. Therefore stress management might be an effective treatment modality for diabetic patients with stress. There are many definitions of coping but probably the most commonly used is that of Pearlin and Schooler [52], who define coping as behavior that protects people from being psychologically harmed by problematic social experiences. Coping serves a protective function that can be exercised in three ways: 1) by eliminating or modifying stressful conditions; 2) by perceptually controlling the meaning of the stressor; or 3) by keeping emotional consequences in bounds. The other commonly used definition is that of Lazarus and Folkman [53], who define it as "constantly changing cognitive and behavioral efforts to manage specific external and/or internal demands that are appraised as taxing or exceeding the resources of the person". In other words, coping allows people to use various skills to manage the difficulties they face in life. However, Carolyn [54] defines stress coping skill as the use of strategies for dealing with actual or anticipated problems and their attendant negative emotions.

There are many methods of stress coping skills. Women are far more likely than men manage stress by reading ( $57 \%$ vs. $34 \%$ for men) and overall, tend to report more stress management activities that connect them with other people, like spending time with friends or family (54\% vs. 39\%) and going to church or religious services (27\% vs. 18\%) [28]. However in our study, only $10.5 \%$ practice worshipping and this was 
actually quite low compared to a study in Latino (57.59\%) [55] and 71\% in Pakistan [56]. R. Chang [39] reports emotional expression is good to buffer rather than amplify the effects of stress. Although emotional expression is a voluntary engagement strategy, perhaps it is not the best means of dealing with daily stress. Talking and expressing feelings to others may serve to reaffirm those feelings and potentially exacerbate them without dealing with the real source of the stress. Emotion-focused coping strategies aim to reduce and manage the intensity of the negative and distressing emotions that a stressful situation has caused rather than solving the problematic situation itself. These coping strategies thus help us feel better but don't solve the source of our distress. Women feel more often than men that they need to control their emotions first with the emotion focused coping and then start using problem focused coping to solve their problem [57]. This might be the reason of keeping calm being the highest coping skill used by stressed women to handle stress in our study, compared to talk to someone or express in words. A study in Japan shows that keeping calm is reported to have a strong association with stress $(P<0.001)$ and 58.3\% of stressed women use this method as stress coping skill [58]. Sharon Galor [57] also states that seeking social support is important as it provides the individual with sympathy, understanding, moral support as well as information, advice and resources. Social support may play a role at two different points in the causal chain linking stress to illness [59]. Support may alleviate the impact of stress appraisal by providing a solution to the problem, by reducing the perceived importance of the problem, by tranquilizing the neuro-endocrine system so that people are less reactive to perceived stress, or by facilitating healthful behaviors [60]. However, social support can only be of help when it conforms to the coping strategies that are most adequate in the stressful situation [61]. However, R. Chang [39] reports that none of the coping styles interacted with total stress to predict blood glucose.

Language barrier and caution towards strangers were limitations in our study as it disabled the ability of interviewer with the respondents. Consequently, our results are likely an underestimate of the true prevalence of pre diabetes. Because the diagnosis of pre-existing diabetes was based on self-report, there is also the possibility that individuals may have incorrectly reported their diabetes diagnosis; for example, those with controlled type 2 diabetes may have wrongfully reported themselves as not having diabetes.

\section{CONCLUSION}

More than half of women respondents in Mukim Sg. Pelek, Sepang Selangor who stressed were at pre diabetes status. Majority of them were housewife with family was the main cause of stress. Intervention program on awareness towards coping with stress positively should be carried out for the residents, not only to reduce stress level among women but also among family members as well as reduce the risk of getting diabetes. There should be also an increased diabetes screening, and potentially earlier identification of case patients and high-risk individuals.

\section{ACKNOWLEDGEMENTS}

We acknowledge and are grateful for the financial help furnished by Cyberjaya University College of Medical Sciences (CUCMS). We are also acknowledging the residents of Mukim Sg. Pelek, Sepang as the respondents of this study as well as the students of CUCMS as the data collectors.

\section{REFERENCES}

[1] WHO, "Strengthening mental health promotion," Geneva, World Health Organization (Fact sheet no. 220), 2001.

[2] Jamsiah M., et al., "Stres dalam kalangan penduduk dewasa luar bandar daerah Hulu Langat Selangor," Journal of Community Health, vol/issue: 16(1), 2010.

[3] APA, "Survey reveals deepening concerns about connection between chronic disease and stress," American Psychological Association, 2012.

[4] U. Ram, et al., "Gender socialization: Differences between male and female youth in India and associations with mental health," International Journal of Population Research, pp. 1-11, 2014.

[5] APA, "Stress and mind/body health," American Psychological Association, 2015.

[6] K. Shamsuddin, et al., "Correlates of depression, anxiety and stress among Malaysian university students," Asian Journal of Psychiatry, vol/issue: 6(4), pp. 318-323, 2013.

[7] K. Glanz and M. D. Schwarta, "Stress, coping \& health behaviour," in K. Glanz, K., B. K. Rimer, \& K. Viswanath (Eds.), "Health behavior and health education," San Francisco, CA, Jossye-Bass, pp. 211-236, 2008.

[8] Norfazilah A., et al., "Quality of life among young adults in rural Selangor: a cross-sectional study," Malaysian Journal of Public Health Medicine, vol/issue: 15(1), pp. 53-61, 2015.

[9] F. Rutters, et al., "The association between psychological stress and mortality is mediated by lifestyle and chronic disease: The Hoorn Study," Social Science Medicine, vol. 118, pp. 166-172, 2014.

[10] S. Wild, et al., "Global Prevalence of Diabetes: Estimates for the year 2000 and projections for 2030," Diabetes Care, vol/issue: 27(5), pp. 1047-1053, 2014. 
[11] Kato M., et al., "JPHC Study Group. Psychological factors, coffee and risk of diabetes mellitus among middleaged Japanese: a population-based prospective study in the JPHC study cohort," Endocr J, vol/issue: 56(3), pp. 459-468, 2009.

[12] NIDDK, "Diabetes, heart disease and stroke," 2011.

[13] IDF, "Diabetes in Malaysia," International Diabetic Federation, 2014.

[14] G. Kaur,., "et al Depression, anxiety and stress symptoms among diabetics in Malaysia: a cross sectional study in an urban primary care setting," BMC Fam Pract, vol/issue: 14(1), pp. 69, 2013.

[15] S. Mallikarjuna, et al., "Prevalence of diabetes mellitus and role of stress in diabetes in rural Pondicherry - An union territory of India," 2012.

[16] Faulenbach M., et al., "Effect of psychological stress on glucose control in patients with Type 2 diabetes," Diabet. Med, vol/issue: 29(1), pp. 128-31, 2012.

[17] T. K. Young and C. A. Mustard, "Undiagnosed diabetes: does it matter?" CMAJ, vol. 164, pp. 24-28, 2001.

[18] L. C. Rosella, et al., "Prevalence of prediabetes and undiagnosed diabetes in Canada (2007-2011) according to fasting plasma glucose and $\mathrm{HbA}_{1 c}$ screening criteria," Diabetes Care, vol/issue: 38(7), pp. 1299-1305, 2015.

[19] C. C. Wing, et al., "What does 'undiagnosed' diabetes really mean?" The New Zealand Medical Journal, vol. 126, pp. 1372, 2013.

[20] A. Gloster, et al., "Psychometric properties of the depression anxiety and stress scale-21 in older primary care patients," Journal of Affective Disorders, vol/issue: 110(3), pp. 248-259, 2008.

[21] $\mathrm{MOH}$, "Clinical practice guideline management of type 2 diabetes mellitus," Putrajaya, Ministry Of Health Malaysia, 2009.

[22] NHMS, "Non-communicable diseases, risk factors \& other health problems," Institute for Public Health (IPH), vol. II, 2015.

[23] APA, "Gender, generations, parents and stress," American Psychological Association, 2014.

[24] G. Malini, "Indian women most stressed in the world," The Economic Times, 2011.

[25] H. Emma, et al., "Division of labor, perceived labor-related stress and well-being among European couples," Open Journal of Preventive Medicine, vol. 2, 2012.

[26] N. Parveen, "Investigating occupational stress among married and unmarried working women in Hyderabad City," Bahria Journal of Professional Psychology, vol. 5, pp. 21-37, 2009.

[27] H. Ingegerd and T. Jan, "Parental stress in mothers and fathers one year after birth," Journal of Reproductive and Infant Psychology, vol. 32, 2014.

[28] APA, "Gender and Stress," American Psychological Association, 2010.

[29] Joshi R and Tomar A. K., "Effect of family environment on behavioural problems and family dynamics," $J$ Res Appl Clin Psychol, vol. 9, pp. 51-6, 2006.

[30] J. Poduval and M. Poduval, "Working mothers: how much working, how much mothers, and where is the womanhood?" Mens Sana Monogr, vol/issue: 7(1), pp. 63, 2009.

[31] P. J. Parameswari, et al., "Stress among Women in Sub Urban Area in South Chennai India," Scholars Journal of Applied Medical Sciences, vol. 3, 2015.

[32] K. M. S. Fatimah, et al., "Prevalence, Associated Factors and Predictors of Depression among Adults in the Community of Selangor, Malaysia," PLOS ONE, vol/issue: 9(4), 2014.

[33] N. R. A. Bakar, "Malaysian Women in Management," GEOGRAFIA Online TM Malaysia Journal of Society and Space, vol/issue: 8(4), pp. 12-20, 2012.

[34] Edimansyah A., et al., "Self-perceived depression, anxiety, stress and their relationship with psychosocial job factors in male automotive assembly workers," Industrial Health, vol. 46, pp. 90-100, 2008.

[35] L. Casey, "Stress and wellbeing in Australia survey 2013: The state of the nation two years on, and Special feature on working Australians," National Psychology Week is an initiative of the Australian Psychological Society, 2013.

[36] V. L. Goetsch and D. J. Wiebe, "Diabetes mellitus: considerations of the influence of stress," in A. J. Goreczny (Ed.), "Handbook of health and rehabilitation psychology," New York, Plenum Press, pp.513-533, 1995.

[37] H. P. Chase and G. G. Jackson, "Stress and sugar control in children with insulin dependent diabetes mellitus," Journal of Pediatrics, vol. 98, pp. 1011-1013, 1981.

[38] J. McCubbin, et al., "Effect of opiate antagonism on stress induced hyperglycemia in obese mice," Diabetes, vol. 36, pp. 18A, 1987.

[39] R. Chang, "The effects of stress and coping styles on blood glucose and mood in adolescents with type 1 diabetes," Carnegie Mellon University, 2009.

[40] J. Napora, "Managing stress and diabetes," American Diabetes Association, 2013.

[41] F. Pouwer, et al., "Does emotional stress cause type 2 diabetes mellitus? A review from the European Depression in Diabetes (EDID) Research Consortium," PubMed - NCBI, 2015.

[42] S. Tsujii, et al., "Diabetes distress, but not depressive symptoms, is associated with glycaemic control among Japanese patients with type 2 diabetes: Diabetes distress and care registry at Tenri (DDCRT 1)," Diabetic Medicine, 29(11), pp. 1451-1455, 2012.

[43] H. S. Minhat and T. R. Hamedon, "Understanding towards diabetes mellitus among rural adult community in Malaysia," World Journal of Medical Sciences, vol/issue: 11(2), pp. 217-221, 2014.

[44] S. M. Johari and S. Shahar, "Metabolic syndrome: The association of obesity and unhealthy lifestyle among Malaysian elderly people," Arch Gerontol Geriatr, vol/issue: 59(2), pp. 360-6, 2014.

[45] I. S. AL-Aboudi, et al., "A cross-sectional assessment of health-related quality of life among type 2 diabetes patients in Riyadh, Saudi Arabia," SAGE Open Medicine, vol. 3, 2015. 
[46] G. R. Letchuman, et al., "Prevalence of diabetes in the Malaysian National Health Morbidity Survey III 2006," Med J Malaysia, vol/issue: 65(3), pp. 180-6, 2010.

[47] A. Pandit, et al., "Disease-related distress, self-care and clinical outcomes among low-income patients with diabetes," Journal of Epidemiology \& Community Health, vol/issue: 68(6), pp. 557-564, 2014.

[48] V. B. Lang, et al., "The association of lifestyle and stress with poor glycemic control in patients with diabetic type 2: A Croatian nationwide primary care cross-sectional study," Croat Med J., vol/issue: 56(4), pp. 357-365, 2015.

[49] C. Crump, et al., "Stress resilience and subsequent risk of type 2 diabetes in 1.5 million young men," Diabetologica, vol/issue: 59(4), pp. 728-733, 2016.

[50] H. L. Wee, et al., "The impact of diabetes mellitus and other chronic medical conditions on health-related quality of life: Is the whole greater than the sum of its parts?" Health and Quality of Life Outcomes, vol. 3, pp. 2, 2005.

[51] Richard S. S., et al., "Stress management improves long-term glycemic control in type 2 diabetes," Diabetes Care, vol/issue: 25(1), pp. 30-34, 2002

[52] L. I. Pearlin and C. Schooler, "The structure of coping," J Health Soc Behav., vol. 19, pp. 2-21, 1978.

[53] R. S. Lazarus and S. Folkman, "Coping and adaptation: The handbook of behavioral medicine," Gentry WD, Ed. New York, Guilford, pp. 282-325, 1984.

[54] C. M. Aldwin, "Stress, coping and development," Second Edition, An integrative perspective, pp. 125, 2007.

[55] M. P. Sasha, et al., "Stressors and coping mechanisms associated with perceived stress in latinos," Ethinicity and Disease, 2015.

[56] M. Mamoona, "What are the coping strategies gynaecologists employ to meet with stressful situations," Journal of the Pakistan Medical Association, 2015.

[57] S. Galor, "Emotion-focused coping strategies," 2012.

[58] S. Chisato, et al., "Gender-Specific Associations of Perceived Stress and Coping Strategies with C - reactive protein in Middle-Aged and Older Men and Women," International Journal Behavioral Medicine, vol. 21, pp. 821832,2014

[59] Cohen, J. N. Jersey, "Lawrence Enlbaum Associates," Statistical power analysis for the behavioral science, 1988.

[60] J. S. House, et al., "Social relationships and health," Science, vol. 241, pp. 540-50, 1988.

[61] S. Cohen and T. A. Wills, "Stress, social support, and the buffering hypothesis," Psychol Bull, vol. 98, pp. 310-57, 1985. 